\title{
Research of Industrial Zone adjacent to Port Planning Based on safety and harmony
}

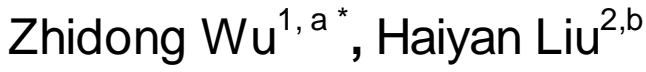 \\ ${ }^{1}$ College of architecture, Dalian Nationalities University, Dalian,China \\ ${ }^{2}$ Dalian Urban Planning\&Design Institute, Dalian, China \\ azd wu@126.com, ${ }^{\mathrm{b}}$ hedy liu@sina.com
}

\begin{abstract}
Keywords: security, harmonious, industrial Zone adjacent to Port
\end{abstract}
Abstract. Taking Deng Shahe Industrial Zone adjacent to Port control detailed planning as an example, puts forward the concept of lower limit control of plot ratio in industrial land use and upper limit of the greening rate, to ensure the rational and intensive use of land resources, we research conditions of land use scientifically, pay attention to ecological protection and security of industrial zone, think highly of the importance of public services and municipal public utilities in Industrial Zone adjacent to Port, building foundation of harmonious society.

Deng Shahe IndustrialZone adjacent to Port is located in Dalian Deng shahe town, the eastern part of Jinzhou New District, Northeast Special Steel Group brought gigantic development opportunity to Deng shahe industrialZone adjacent to Port. Planning of IndustrialZone adjacent to Port, is not only a planning task, more important thing is considering the base of natural conditions fully, with security as the dominant, research new methods and planning ideas, creating a new industrial district which structure reasonable, operation efficiently, society and the nature harmonious.

\section{Evaluation of the Land Suitability}

General land use planning often focus on the land location, traffic conditions only, based these information to determine its function area division and the nature of land use, research on the suitability of land is less. Through analysis and Research on the elements which influence land construction such as local geography,elevation,slope, to ensure the intensive use of land.

Geography. The base belongs to low hill slow floodplain, formed by the board in Deng Shahe and its branch impact small plain, and its terrain is relatively flat. Deng Shahe flow into the seaon the west side of Township, both sides of Deng shahe river formed ponds and salt flats. At present, most salt flats are backfilled, turned into industrial construction land. With the ecological regulation of Deng Shahe river, it will provide a good ecological environment for the city.

Elevation analysis. East of the base is low,the west is high,from the north to the south direction, the center of base is high, both sides are low. Terrain of the base interleaves, forming a plurality of ridge and valley lines, Rain of the base inflow to Deng Shahe River. The commanding heights is located in the top of central hill, 39 meters above sea level, the lowest point is located in beach and salt flats of Deng Shahe river, 0.4 meters above sea level. (Figure 1)

Slope analysis. The slope of the base is gentle, it is suitable for construction. The slope of Current township and village construction area is gentle; salt flats and fish pond land are filled,their elevations are filled to 5-7 meters; the South West of Township Land undulating changes greatly, with average slope 1\%-5\%.

Comprehensive evaluation. Through the analysis to main influencing elements of construction land such as geography, slope and elevation, planning land will be divided into three categories. The first style construction area is agricultural land,construction land of the towns and villages which slope is slow, the geological condition is good, these districts are suitable for construction . the second style construction area refers to salt flats, beach land regulation, which can become good construction land. The third style area is not 
suitable for construction areas which are the rivers and coastal protection area, coastal shoal, through renovating coastline, building ecological green land and coastal park.

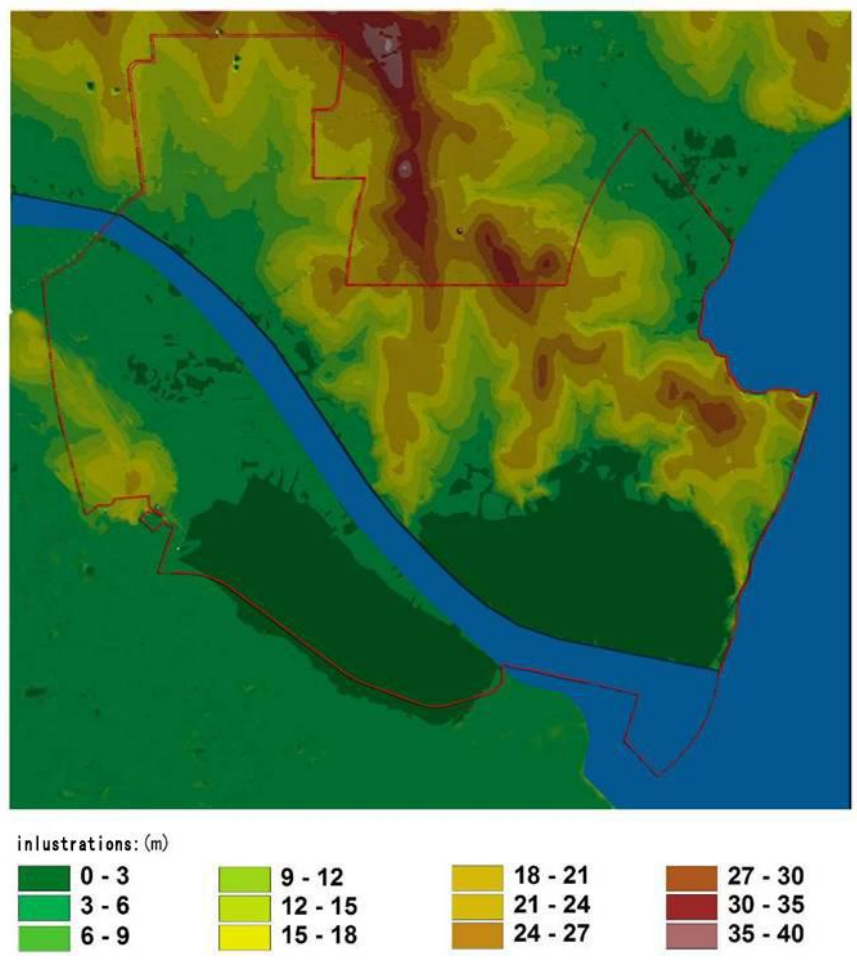

Figure 1. elevation analysis.

\section{The Intensity Development Control of the Industrial Area and the Living Area}

In order to ensure the rational use of land intensive, floor area ratio of industrial land control adopt lower limit and upper limit of green rate. At present, the conventional approach only control the upper limit, namely " $<$ ?" which goal is the balance between volume of construction and ecological environment, public facilities and municipal facilities. Previous industrial development reflected its other side: a few constructions caused waste of the land and facilities, benefits reducing. However technology regulations in China has not the lower limit, so it is reasonable that floor area ratio adopt lower limit and upper limit of green rate.

There is fine steel manufacturing area in the west of Industrial Zone adjacent to Port, and eastern is auto parts industry equipment manufacturing and other industrial land. Floor area ratio of Industrial land and land for warehouses is above 0.6 ,building density is above $35 \%$, green rate below $20 \%$. The floor area ratio of residential land and public facilities control upper limit and green rate lower limit, according to the standard control its construction, confirm reasonable floor area ratio and green rate.

\section{Pay Attention to Ecological, Creating a Good City Landscape}

Bohai sea is on the verge of southeast of the base , the north relies on the mountain, big black mountain landscape and the Chengshantou Nature Reserve is a natural green barrier, there are dengshahe river , matihe river and dalijiahe river from west to East into the sea in the base; there are many coastal resources such as owned beach, floodplain, wetland and other scarce, natural conditions superior.

Planning to make full use of industrial waterfront landscape and waterfront park landscape, to build urban coastal landscape belt. combined with the blue line of deng Shahe river, the shrub planting area of trees format protective forest belt, we set the pedestrian space and leisure venues, build riparian ecological park and green landscape belt. Riverside landscape belt includes the green line,near river ,broad ecological forest and broad 
estuary wetlands. We set the protective green on both sides between the industrial area and residential area and the railway,Combined with the industrial noise, dust control requirements, to reduce the impact on the living environment of the humanities; industrial symbol characteristics of the various pieces as the ornament, such as a famous enterprise management home Sculpture Park, increase the cultural connotation of harmonious development between human and the nature.

\section{Perfect the Public Service Facilities and Infrastructure Facilities}

In order to promote the coordinated development of industrial district, it is necessary to improve the overall service level, improve the public facilities. Perfect public service facilities and municipal infrastructure is the support and guarantee of the development of industrial zone, on the basis of the population, the service radius and traffic environmental requirements, we set up public service facilities such as schools, hospital, neighborhood offices and police station.

Public facilities include the public service facilities and municipal facilities. Public service facilities is the soft environment of the industrial zone transformation and development. Scientific development and harmonious society need increase content of science and technology, pay attention to scientific progress and improve the quality of workers. We set up service facilities such as mechanic occupation training, technology exchange for industrial zone not only, but also in order to ensure the accessibility and enough radiation distance, we put up sports and leisure, exhibition, entertainment facilities of different scale.

In the municipal facilities, we improve the road system planning, adjust layout of water supply and drainage, power supply, fire protection and pipe network reasonable, strengthen the networks construction of posts and telecommunications especially enterprises between the high-speed optical fiber network, and construct major infrastructure has a hub, functional and network characteristics firstly, on the basis of infrastructure, we solved many problems such as the site of sewage and thermal power plant, site and line of $220 \mathrm{kV}$ substation, the fire station layout, Kunda cast pipe and site of air Liquide.

Site of sewage and thermal power plant. we confirm the position of large infrastructure such as sevage and thermal power plant,position of sevage need consider the factors of site elevation and the recent and long time sevage discharge, site of thermal power plant need consider the factors such as the use of special railway line and thermal load.

Location and route of $220 \mathrm{KV}$ substation. We confirmed the location and route of $220 \mathrm{KV}$ substation, the location need consider the factors such as the distance to The Northeast Special Steel Group, High tension corridor, relocation and recent implementation, the width of high tension corridor is $174 \mathrm{~m}$ of $220 \mathrm{kv}$ and $66 \mathrm{kv}$,double lines of $66 \mathrm{kv}$ is $45 \mathrm{~m}$, single line of $66 \mathrm{kv}$ is $25 \mathrm{~m}$.

Layout of fire station. On the basis of Dalian city fire planning, discussion with the fire department, combined with the actual situation, we set four fire stations, there are three standard fire stations, one professional fire station which is in charge of The Northeast Special Steel Group.

Current situation of pipeline and road section. We migration present situation of cable and water pipe line in the north of power plant to both of jiangda road, to ensure the The integrity of industrial land, port road and dagang road are completed, connected the actual road section, make full use of present green belt, re arrangement of municipal pipelines, to meet the need of short and long term construction of Industrial Engineering.

\section{Smooth Road and Traffic}

Planning focus on improving urban external traffic system, optimize the internal traffic organization, set up comprehensive traffic system gathered railway, port and road as a whole. organize external traffic of Industrial Zone reasonably, planned wharf and special railway lines, develop a variety of transportation mode.

In road pattern planning, we emphasize the features of coastal city; to meet the needs of urban function, format axis radiation shape pattern, facing the ocean is annular expansion characteristics. According to the 
traffic demand characteristics of industrial zone, we select road network structure of grid choice in Industrial Zone, to determine the distance between the main road is $1 \mathrm{~km}$, space of secondary roads is $300 \mathrm{~m} \mathrm{--} 400 \mathrm{~m}$, avoiding the road more than normal wide. Among each functional zones, we formed convenient road to ensure the system traffic effectively connected.

On public transport, we increase the density of bus station, ensuring urban station spacing is $500-800$ meters, suburban station is 800 - 1000 meters, so that most of the residents do not walk more than 300 meters, can be the nearest bus ride. We reserved track traffic line, established optimizational public traffic system, and do a good job of connecting different public transport modes, complement each other among the city bus, light rail transit and long-distance passenger transportation, reduce transfer times, facilitate the residents nearby.Planning rail transitl station and maintenance site.

\section{Assuring Safe of Industrial Zone Adjacent to Port}

The drainage of Northeast Special Steel Group and surrounding district. Considering from the disaster prevention of Northeast Special Steel Group, we set four drainage pumping stations according to a 50 year flood protection standards to improve the safety of Industrial Zone adjacent to Port, solved waterlogging problem of field in special period. Local road located in the middle of two channels, combined with the road transverse slope design, water to both sides of the ditch, solved drainage problems of the road.

River blue line control. There are three rivers in planning area, to ensure the safety of industrial zone, we control the scope of each river blue line . channel width of Deng Shahe river from upstream to downstream is 200 -- 350 meters, its blue line width is 230 -- 410 meters, width of to the sea is 500 meters; width of matihe River from upstream to downstream is 44 meters -- 10 meters, considering factors such as special railway line, its blue line width is 66 -- 26 meters width of daliJia river from upstream to downstream is 28 -- 51 meters, its blue line width control 40 -- 65 meters.

Vertical design. Combined with the existing topography, we research vertical of road and site, avoided the big cutting and fill, to reduce project cost. According to the specification, the lowest design elevation of coastal is 4.5 meters; the road longitudinal slope is not less than $0.3 \%$.

\section{Conclusion}

From the angle of city comprehensive disaster prevention, to improve the safety board in DengShaHe IndustrialZone adjacent to Port, we research on special railway lines, road channel design, coastal area and the vertical site etc. with the relevant departments many times, At present, the project is being implemented, in the implementation process, it will encounter various contradiction probably, we can track and solve these contradictions, carry out the idea of harmonious society to planning.

\section{References}

[1] Xu long.2011, 03. from the perspective of industrial development of Lingang Industrial Area Planning -Taking Qinzhou port industrial zone as an example.city.

[2] Wu Xianwen.2005.06. control and compatible of industrial zone control detailed planning . planners:

[3] Dong Fei.2006.09.Thought on the Planning and Construction of the Urban Industrial Park of Hanzheng Street in Wuhan, planners. 